\title{
Impact of Abusive supervision on Organizational Citizenship Behavior: Mediating role of Job Tension, Emotional Exhaustion and Turnover Intention
}

\author{
Faique Bin Fakhar \\ Foundation University, Islamabad
}

\begin{abstract}
The research was designed to find out the impact of abusive supervision on OCB and to see what mediating role do the three variables i.e. job tension, emotional exhaustion and turnover intention play in the association of abusive supervision and organizational citizenship behavior. A total of 205 responses were gathered for the analysis of the study. Analysis was done using Simple regression, Multiple Regression and Baron and Kenny tests. The results concluded that the mediating variables didn't have any relationship with the dependent variable. Due to this no mediation existed among the dependent and independent variable. Abusive supervision, however, was found to be in a positive relationship with Organizational citizenship behavior. A positive relationship was also found between abusive supervision and 3 mediating variables ( job tension, emotional exhaustion and turnover intention).
\end{abstract}

\section{Introduction}

Barney (1991) pointed out three mediums that give competitive advantage to the organization in highly aggressive atmosphere. These are Human-capital resources, Physical-capital resources and Organization-capital resources. But the Human-capital resources supports as a crucial function in most advantageous use of the latter two. The Human-capital resources are interconnected with organization ability to perform as a whole and contribute excessively in mounting and supporting competitive advantage for the firm. Further, Lusch \& Serpkenci (1990) focuses on the effectual management of these possessions for having a firm position in the competitive market and to gain a leadership position in industry. Job tension and Emotional Exhaustion and turnover intention, as mediating variables have many independent variables for example, abusive supervision, ingratiation, positive affects, organization internal and external environment, peer influences, supervision and so on. In this study, the researcher has focused the study to examine the effects of abusive supervision on employees' pessimistic outcomes.

Supervision means to control LeBlanc \& Kelloway,(2002) and lead the things in an organized manner where as the abusive supervision refers to perceptions of lower staff regarding their supervisor's nonphysical unfriendly attitude toward them (Kennedy, Homant \& Homant, 2004). Abusive supervision affects both the employees and the employers (Milam, Spitzmueller \& Penney, 2009).

In the past the literature of management has highlighted in majority of cases different fruitful and constructive management behaviors and their optimistic implications, a minute but upcoming area of research is focusing on the consequences of unwanted management responses. Research on unwelcomed management behaviors suggested that these behaviors had an unfavorable impact on employee attitudes (e.g., job satisfaction and organizational commitment) and employee behaviors (e.g., organizational deviance and organizational citizenship behaviors; for a full review, Tepper, 2007). These outcomes recommend that a more detailed consideration of how managerial actions impact the attitude of the employees and behavior should include investigations of both wanted and unwanted managerial responses.

Abusive Supervision is the significant area to study because various minor acts of workplace aggression can eventually lead to workplace violence (Baron \& Neuman, 1998). This study is an extension in the model of the Shahid Nawaz Khan, Imran M. Qureshi and Hafiz Israr Ahmad (2010) as a new variable i.e. organizational citizenship behavior. The study highlights the mediating role of job tension, emotional exhaustion and turnover intension on the relationships of abusive supervision and organizational citizenship behavior. So far no one has attempted to identify such mediating role of job tension, emotional exhaustion and turnover intension on such relationship so the research will definitely provide with a fruitful outcome.

\subsection{Problem Statement}

This study explore, investigates the mediating role of job tension, emotional exhaustion and turnover intention between the abusive supervision and organizational citizenship behavior in the banking industry employees. 


\subsection{Objective of the Study}

The objectives of the study are:

- To study how abusive supervision and organizational citizenship behavior are related.

- To study the relationship between abusive supervision, job tension, emotional exhaustion, turnover intention and organizational citizenship behavior.

- To explore how much effect job tension, emotional exhaustion, turnover intention have on organizational citizenship behaviors of employees

- To explore the mediating role of job tension, emotional exhaustion and turnover intention on the relationship of abusive supervision and organizational citizenship behavior.

\subsection{Significance of the Study}

This study would help students and researchers of management sciences and human resource management. It will help organizations to recognize the link between abusive supervision and negative employee outcomes and choosing appropriate measures to evaluate and analyze the negative employee outcomes is the purpose of this paper. If the organization can control the abusive supervision environment, it can lead to increase employee retention, employee loyalty and citizenship behavior in a long run. Further it would facilitate the field of human resource and economy as a whole.

\section{Literature Review}

Tepper (2000) used the organizational justice theory to review the abusive supervision by considering interactional justice and the organizational justice and the positive outcomes of the justice are the job satisfaction, life satisfaction, organizational commitment whereas an unjust environment results work life conflict and psychological distress. Meyer and Allen (1991) concluded in their study that the continuous commitment is the basic need of employees for organizational attachment. when organizations are embedded with the unjust environment then the employees feel that their work is not recognize by their supervisors and not worthy for the organization (Konovsky \& Cropanzano,1991). The results of the Tepper (1991) showed that when the attitude of the supervisor is abusive then the employee reported lower job satisfaction, lower commitment and all the positive factors go against the desired outcomes for the organizations. Bennett et al. (2009) concluded that the subordinates prefer to be quite rather than to argue when their employers adopt the abusive behavior. Their results showed a significant positive relationship between the abusive supervision and the employees' workplace deviance. They also include in their study that the psychological factor of the employees also contribute in the reaction towards the abusive supervision of the supervisor. The behaviors that might $\mathrm{b}$ included in the abusive supervision are public criticism, rudeness, breaking promises, inconsiderate actions and the silent treatment (Bies, 2000). A counterproductive work behavior is the attitude of the employees that will adversely affect the organization in terms of harming the stakeholders such as clients, customers, coworkers and supervisor (Spector \& Fox, 2005). Jannifer et. Al. (2010) found in their research that the employee engagement in counterproductive work behavior id related to the interpersonal conflicts in the workplace. Namie $(2003,2007)$ says that abusive supervision of the employee leads to the termination of talented employees voluntarily or involuntarily. Employees coping with the abuse would affect the organization reputation (Lutgen - Sandvik \& McDermut, 2008). The feel of powerless and being control results the depression and results the aggressive behavior ( Bennet, 1998).

Some researchers consider psychological dysfunction as a stress (Ivancevich \& Matteron , 1980 a). Job stress is when the individual's feeling conflict with the perceived happening of the organization. Deviation from the normality creates stress (Margolis \& Kroes, 1974). To overcome the stress, stressor must be removed immediately. Same level of stress may leads to number of different outcomes; considerable things include intensity of the stress and the duration of the stress. Kumar \& Ghadially (1986) used the variables interpersonal trust, alienation and feeling about job performance. Their relationship with the job stress is positive in case of alienation whereas the remaining two factors showed negative relation with the job stress. Workplace politics is also one of the reasons of the job stress reported by many researchers. Gilmore et. Al. (1996) suggested that the main stressor for the stress is the organizational politics and the work environment conflicts which produce non supportive outcomes at both individual and the organizational level. Ferris et. al. (1996) also proposed almost the same results that the job anxiety and the organizational politics are empirically related. Gilmore (1996) tries to prove that the aggressive behavior in highly political environment organization results individual conflicts and the groups disharmony. Eran (2000) conducted study on the relationship among the politics, job distress and aggressive behavior in the organization and concluded that organizational politics is optimistically related to the job stress and job stress is pessimistically associated to job satisfaction and organizational commitment and the job stress is significantly related to the aggressive behavior. Cropenzano (1997) concluded in his study that the consequences of the work stress always have negative impact on the individuals, organizations and on the economy as a whole. 
Employees become frustrated as they find any negative deviation from their past job performance in their present performance. Burnout phenomena of the job start with the emotional exhaustion (Gaines \& Jermier, 1983; Maslach, 1982). Conflict and ambiguity are the main role stressor of the emotional exhaustion. Boles et al. (1997) found that only the role conflict shows significantly impacting on the emotional exhaustion. Brown \& Peterson (1993) considered the job satisfaction, job performance, organizational commitment and turnover intentions are the role stressors that have direct effect on the emotional exhaustion. Singh et. al. a significant relationship between the role conflict and the sales person job performance. Emotional exhaustion created by the job performing has two reasons, first is when the employee feel tension and the emotional dissonance and the second is when the resources are taken away even when the employee playing his part with effort (Wharton, 1993). Emotional dissonance has a direct effect on the emotional exhaustion (Abraham,1998). If internal feeling is aligned with the expression then the emotional dissonance is less. And if the relationship examined then we come to know that the relationship between internal feeling and the emotional exhaustion is weaker than the relationship between artificial behavior and the emotional exhaustion (Hochschild 1983). Tepper (2000) found abusive supervision as another factor that is positively related to the emotional exhaustion. Brough \& Frame (2004) consider job satisfaction as the strongest variable that predicts the turnover intentions. According to the Ashforthe (1997) \& Tepper (2000) identified the turnover intention, high level of emotional exhaustion, organizational commitment and the low level of job satisfaction as the consequences of the abusive supervision. Turnover is always costly for organizations because the organization needs to hire, train and develop the new employee (Alexander, Bloom \& Nucholas, 1994). The more supervisors adopt the abusive behavior the more organizational justice would be effected which ultimately results the employee turnover (Tepper, 2000).

Organization citizenship behavior is something beyond the minimum level of the job requirement like promoting the co-worker, organization's internal groups and organization as a whole (Lovell, Kahn, Anton, Davidson, Dowling, et al., 1999). Many studies showed that culture is the main factor of influence on organizational citizenship behavior (Coyne \& Ong, 2007; George \& Jones 1997; Lam, Hui \& Law, 1999; Paine \& Organ, 2000). Individual perform OCB if this behavior is align with their values (Shamir 1996). Zellar, Tepper and Duffy (2000) reported a significantly negative relationship between the abusive supervision and the organization citizenship behavior.

Hence, the projected research model can be applied to analyze the impact of abusive supervision on organizational citizenship behavior with the mediating role of other three variables (Job tension, Emotional Exhaustion, Turnover Intension). Subsequent hypothesis are inferred through the theoretical framework.

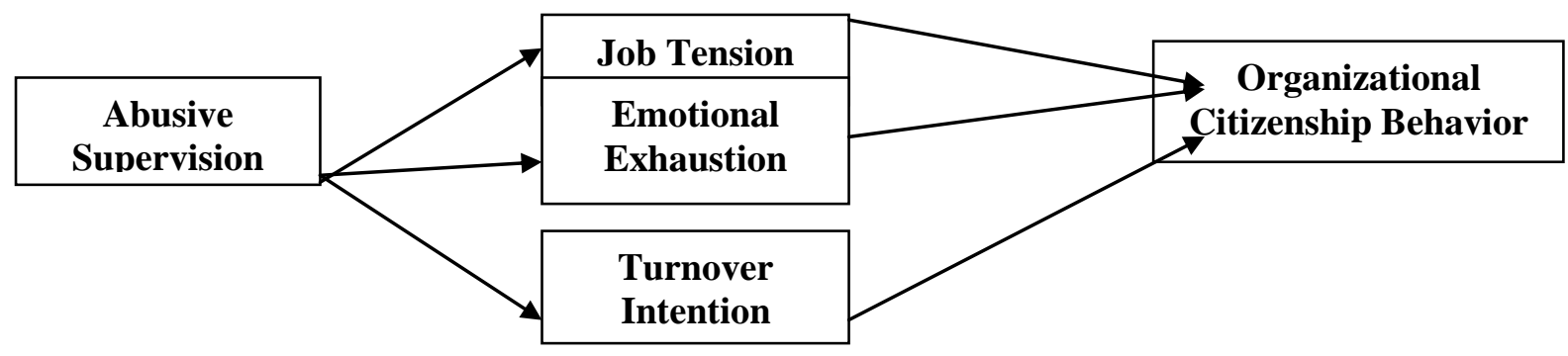

H1: Abusive supervision impacts the job tension positively.

H2: Abusive supervision impacts the emotional exhaustion positively.

H3: Abusive supervision impacts the turnover intention positively.

H4: Abusive supervision has a positive effect on organizational citizenship behavior.

H5: Job Tension has a mediating effect in the relationship of abusive supervision and organizational citizenship behavior.

H6: Emotional Exhaustion has a mediating effect in the relationship of abusive supervision and organizational citizenship behavior.

H7: Turnover intension has a mediating effect in the relationship of abusive supervision and OCB.

\section{Research Methodology}

The current study was cross-sectional and causal in nature. A total of 205 respondents were selected for this study from banks in twin cities of Pakistan i.e. Rawalpindi and Islamabad. Employees were selected from Bank Alfalah, Askari Bank Limited, Meezan Bank Limited, NIB Bank, Bank Dubai Islamic and Faysal Bank Limited. Data was collected through questionnaire. Tepper's (2000) 15-item scale was used to measure abusive supervision. House \& Rizzo's (1972) 7-item subscale was used to measure job tension, Maslach \& Jackson's (1981) 9 scale was used to measure emotional exhaustion whereas three items scale of Tepper, Carr, Breaux, 
Geider, Hu, Hua (2009) was used for measuring TI . OCB was measured by using the four dimensional scale of Mooram and Blakely (1992).

\section{Data Analysis and Discussion}

Data was analyzed by using correlation, regression and barron and Kenny tests.

Table 4.1 Multiple Regression Analysis

\begin{tabular}{|l|c|c|c|c|c|c|c|c|c|c|c|c|}
\hline & \multicolumn{3}{|c|}{ Job Tension } & \multicolumn{3}{c|}{$\begin{array}{c}\text { Emotional } \\
\text { Exhaustion }\end{array}$} & \multicolumn{3}{c|}{ Turnover Intention } & \multicolumn{3}{c|}{$\begin{array}{c}\text { Organization } \\
\text { Citizenship Behavior }\end{array}$} \\
\hline $\begin{array}{l}\text { Abusive } \\
\text { Supervision }\end{array}$ & Beta & $\mathbf{t}$ & $\mathbf{p}$ & Beta & $\mathbf{t}$ & $\mathbf{p}$ & Beta & $\mathbf{t}$ & $\mathbf{p}$ & Beta & $\mathbf{t}$ & $\mathbf{p}$ \\
\cline { 2 - 12 } & .669 & 9.136 & $\begin{array}{l}0.00 \\
0\end{array}$ & .669 & $\begin{array}{l}9.93 \\
4\end{array}$ & $\begin{array}{l}0.00 \\
0\end{array}$ & .634 & $\begin{array}{l}8.31 \\
3\end{array}$ & $\begin{array}{l}0.00 \\
0\end{array}$ & -.284 & -3.009 & .003 \\
\hline
\end{tabular}

Table 4.2 Simple Regression analysis

\begin{tabular}{|l|c|c|}
\hline & t Value & p Value \\
\hline Job Tension & -.948 & .346 \\
\hline Emotional Exhaustion & -1.152 & .252 \\
\hline Turnover Intension & .804 & .423 \\
\hline
\end{tabular}

Table shows that the first hypothesis of our study is true that a positive relation exists between abusive supervision and job tension $(\mathrm{t}=9.136, \mathrm{p}<.05)$. Our second hypothesis, a positive association exists between abusive supervision and emotional exhaustion, is true $(\mathrm{t}=9.934, \mathrm{p}<.05)$ through the regression analysis which showed that abusive supervision is associated with emotional exhaustion with the strength of $66.9 \%$ as shown in table 4.1. Hypothesis 3 of this study proved to be true that there is a positive association between abusive supervision and turnover intention as $(\mathrm{t}=8.313, \mathrm{p}<.05)$. Hypothesis 4 was found also true because results of table 4.1 showed that a positive relationship exists among abusive supervision and organizational citizenship ( $p$ $<0.05$ ).

Referring to table 4.2, none of the mediators had any effect on the depending variable. Thus, Baron and Kenny test could not established for hypothesis 5, 6 and 7 of the study which stated that job tension, emotional exhaustion and turnover intentions mediates the effect of abusive supervision in organizational citizenship behavior as no significant effect was found of all mediating variables on the dependent variable.

\subsection{Conclusion}

The main thought behind this learning was to create the relationship of abusive supervision on OCB regarding employees of the banking division. This study authenticated that:

- Job Tension, Emotional Exhaustion and turnover intension were not found to be in a relationship with organizational citizenship behavior. As circumstances of mediation did not occurred therefore, the mediation test was not applicable on this relationship.

- Abusive supervision positively relates with Organizational citizenship behavior.

- It was also concluded from the results obtained from the analysis that there is a significant affiliation among abusive supervision and mediating variables.

\section{References:}

[1]. Wayne, J.S., Hoobler.J., Marinova.V.S., \& Johnson.M.M.: Abusive Behavior: Trickle-down effects beyond the dyad. Academy of Management

[2]. Brian T., Gregory.T.B., Osmonbekov.T. \& Gregory.T.S., (2009). Abusive supervision and organizational citizenship behaviors: An examination of potential boundary conditions. Northern Arizona University Working paper series, 9-11.

[3]. Poon.M.L.J. (2011). Effects of abusive supervision and coworker support on work rnanagement. International Conference on Economics, Business and Management, Vol 22.

[4]. Grandey.A.A (2003). When "The show must go on": Surface acting and deep acting as determinants of emotional exhaustion and peer-rated service delivery. Academy of Management faurnat, Vol 46, (No.1), 86-96.

[5]. Bennett.J.T. (2000). Consequences of abusive supervision. Academy of Management Journal, Vol 43. (No.2) 178-190.

[6]. Roberth. M, Gerald L.B. \& Brian P.N., (1998). Does perceived organizational support mediate the relationship between procedural justice and organizational citizenship behavior?. Academy of Management Journal 1998, Vol 41, (No.3), 351-357.

[7]. Donald.E.P., \& Thomas.A.D. (1983). Organizational Determinants of Job Stress. Organizational behavior and human performance, (No 32), 160-177.

[8]. Wilmar.B.S., Schaufeli., Marisa.S., Vicente.G-R., \& Arnold.B.B. (2002). the measurement of engagement and burnout: A two sample confirmatory factor analytic approach. Journal of happiness studies, 3, 71-92.

[9]. Tsung.Y.W. \& Changya.H. (2009). Abusive supervision and employee emotional exhaustion dispositional antecedents and boundaries. Group \& Organization Management. Vo 34, (No.2), 143-169

[10]. Yu.C.W. (2013). OCB and turnover intention: When human capital meets abusive supervision. Business and Information.

[11]. Jehad.M., Farzana.Q.H. \& Mohmad.A.A. (2011). Job satisfaction and organizational citizenship behavior: An empirical study at higher learning institutions. Asian Academy of Management Journal, Vol 16, (No.2), 149-165. 
[12]. Bennett J.T., Jon.C.C., Denise.M.B., Sharon.G., Changya.H. \& Wei.H. (2009): Abusive supervision, intentions to quit, and employees' workplace deviance: A power/ dependence analysis. Organizational Behavior and Human Decision Processes, 109, $156-167$.

[13]. Kenneth J. H., K. M.K., \& Suzanne.Z. (2007). An investigation of abusive supervision as a predictor of performance and the meaning of work as a moderator of the relationship. The Leadership Quarterly, 18, 252-263.

[14]. Kelly.L.Z., Bennett.J.T., Michelle.K.D., (2002). Abusive Supervision and Subordinates' Organizational

[15]. Citizenship Behavior. Journal of Applied Psychology, Vol.87, (No.6), 1068-1076.

[16]. Lei.W., Kim.T.H., Leonel.P., \& Jon.P.H., (2010). Five dimensions of organizational citizenship behavior:

[17]. Comparing antecedents and levels of engagement in China and the US. Springer Science and Business Media.

[18]. Feng.W., \& Steven S., (2011). Tit for tat? Abusive supervision and counterproductive work behaviors: The moderating effects of locus of control and perceived mobility. Springer Science \& Business Media.

[19]. Emin.B., David.W.C., Mark.J., William.C.M. The Role of Emotional Exhaustion in Sales Force Attitude and Behavior Relationships.

[20]. Shahid.N.K., Imran.M.Q., Hafiz.I.A., (2010). Abusive Supervision \& Negative Employee Outcomes. European Journal of Social Sciences, Volume 15, (No.4).

[21]. Meow. L.E., Chan., D.J.M. Abusive supervision through the lens of employee state paranoia.

[22]. Ragins, B. R., \& Cotton, J. L. (1999). Mentor functions and outcomes: A comparison of men and women in formal and informal mentoring relationships. Journal of Applied Psychology, 84, 529-550.

[23]. Restubog, S. L. D., Scott, K. L., \& Zagenczyk, T. J. (2011). When distress hits home: The role of contextual factors and psychological distress in predicting employees' responses to abusive supervision. Journal of Applied Psychology, 96, 713-729.

[24]. Rhoades, L., \& Eisenberger, R. (2002). Perceived organizational support: A review of the literature. Journal of Applied Psychology, 87, 698-714

[25]. Rynes, S. L., Bartunek, J. M., Dutton, J. E., \& Margolis, J. D. (2012). Care and compassion through an organizational lens: Opening up new possibilities. Academy of Management Review, 37, 503-523.

[26]. Robert.H.M., \& Gerald.L.B., (1995). Individualism-collectivism as an individual difference predictor of organizational citizenship behavior. Journal of organizational behavior, Vol 16, 127-142.

[27]. Kisamore, J.L., Jawahar, I.M., Liguori, E.W., Mharapara, T.L., Stone.T.H., (2010). Conflict and abusive workplace Behaviors: The moderating effects of social competencies.

[28]. Moorman, R.H., Harland, L.K., (2002). Temporary employees as good citizens: Factors influencing their OCB Performance. Journal of Business and Psychology, Vol 17, (No.2)

[29]. Maslach, C., Jackson, S.E. (1981). The measurement of experienced burnout. Journal of occupational behavior. Vol. 2 , 99-113.

[30]. Bennett J. T., (2000). Consequences of Abusive Supervision. The Academy of Management Journal, Vol.43, (No.2), 178-190.

[31]. Starratt, A. \& Grandy, G. Young workers' experiences of abusive leadership.

[32]. Thau, S., Bennett, R.J., Mitchell, M.S., \& Marrs, M.B., (2008). How management style moderates the relationship between abusive supervision and workplace deviance: An uncertainty management theory perspective.

[33]. Harris, K.J., Marett, K., \& Harris, R.B. An investigation of the impact of abusive supervision on technology end-users.

[34]. Van der Doef, M., and Maes, S (1999). The Job Demand-Control(Support) Model and psychological well-being: A review of 20 years of empirical research. Work \& Stress, Vol 13, (No.2), 87-114.

[35]. Wang, P., Lawler, J.J., and Shi, K. (2010). Work-family conflict, self-efficacy, job satisfaction, and gender: Evidences from Asia. Journal of Leadership \& Organizational Studies, 17, 3, 298-308.

[36]. Wynekoop, J., and Walz, D. (2000). Investigating traits of top performing software developers. Information Technology \& People, Vol 13, (No.3), 186-195.

[37]. Yi, M.Y., and Hwang, Y. (2003). Predicting the use of web-based information systems: Self efficacy, enjoyment, learning goal orientation, and the technology acceptance model. International Journal of Human-Computer Studies, 59, 431-449.

[38]. Yukl, G (1989). Managerial leadership: A review of theory and research. Journal of Management, 15, $251-289$.

[39]. Zellars, K., Tepper, B., and Duffy, M. (2002). Abusive supervision and subordinates' organizational citizenship behavior. Journal of Applied Psychology, 87, (No 6), 1068-1076.

[40]. Borman, W. C., \& Motowidlo, S. J. (1997). Task performance and contextual performance: The meaning for

[41]. personnel selection research. Human Performance, 10, 99-109.

[42]. Borman, W. C., White, L. A., \& Dorsey, D. W. (1995). Effects of rate task performance and interpersonal factors on supervisor and peer performance ratings. Journal of Applied Psychology, 80, 168-177. 